\title{
A Study on the Adhesion of Styrene-Butadiene Rubber with Red Kaolinite on Aluminum Surface
}

\author{
I. M. Alwaan ${ }^{1,2}$ \\ ${ }^{1}$ Materials Engineering Department, College of Engineering, Kufa University, Najaf, Iraq \\ ${ }^{2}$ Faculty of Chemical Engineering, Universiti Teknologi Malaysia (UTM), 81310 Johor Bahru, Malaysia \\ Correspondence should be addressed to I. M. Alwaan; ism10alw@yahoo.com
}

Received 9 October 2013; Accepted 28 October 2013; Published 19 January 2014

Academic Editors: G. Bayramoglu and M. E. R. Shanahan

Copyright ( 2014 I. M. Alwaan. This is an open access article distributed under the Creative Commons Attribution License, which permits unrestricted use, distribution, and reproduction in any medium, provided the original work is properly cited.

\begin{abstract}
The shear stress, strain, and modulus of styrene-butadiene rubber adhesive with and without kaolinite additive were studied on the aluminum surfaces to know the convenience of it in aluminum industries. The adhesives were cured at temperature of $200^{\circ} \mathrm{C}$ for different curing times $(10,30,40$, and $50 \mathrm{~min}$ ) with and without $50 \mathrm{wt} \%$ kaolinite additives. The result found was good adhesion for styrene butadiene rubber adhesive without kaolinite additive and very poor adhesion with kaolinite additive. It was found that the maximum shear stress of adhesive without kaolinite additive was $2.3 \mathrm{kN} / \mathrm{m}^{2}$ with elongation of $0.23 \%$ and modulus of $100 \mathrm{kN} / \mathrm{m}^{2}$ at curing temperature of $200^{\circ} \mathrm{C}$ for period of time of $40 \mathrm{~min}$. From images of adhesives after breaking of samples, the adhesive without additives failed because both adhesion and the cohesive energies of adhesive were failure; meanwhile, the failure of adhesive with kaolinite additive was due to failure in cohesive energy only.
\end{abstract}

\section{Introduction}

Rubber-based adhesives, also called elastomeric adhesives, are widely used in industrial and household applications. In fact, about one-third of the adhesives used in the world are made from natural or synthetic rubbers. Some of the elastomeric adhesive systems showing industrial importance in recent years are the following: (1) pressure-sensitive tapes and labels; (2) construction adhesives; (3) contact adhesives; (4) hot-melts packaging and bookbinding adhesives; (5) high-strength structural applications for aircraft, automotive, and construction [1].

The previous studies have included that the adhesive strength variation in SBR rubber/polyurethane adhesive joints was consistent with the variation in surface chemistry, wetability, and topography of the treated SBR rubber [2]. The high-performance SBR compound modified asphalt can be made with the addition of polyphosphoric acid (PPA), styrene-butadiene rubber (SBR), and sulfur. The effects of PPA, SBR, sulfur on the physical properties, the dynamic rheological properties, the high-temperature storage stabilities, the morphologies and the internal structures of asphalts were studied [3].
Polymer modification of asphalt binders has increasingly become the norm in designing optimally performing pavements, particularly in the United States, Canada, Europe, and Australia. Specific polymers that have been used include SBR [4]. The effect of the bulk deformation on rubber adhesion, that is, effect on the surface free energy of two rubber compounds filled with various loading fractions of carbon black, natural rubber (NR), and styrene-butadiene rubber (SBR), was studied [5]. Low-pressure plasma treatment has been demonstrated to be suitable to increase the surface energy and adhesion of synthetic sulfur-vulcanized styrenebutadiene (R2) rubber [6].

A variety of solvent-free methods to retreat shoe-soling materials have been examined. With thermoplastic rubber SBS and vulcanized rubber SBR, it was necessary to chemically modify their surfaces to achieve good adhesion [7]. Ethyl-, propyl-, and butyl-acetates (EA, PA, and BA, resp.) were used as solvents for trichloroisocyanuric acid (TCI) to chlorinate styrene-butadiene rubber (SBR). Stress-strain measurements were carried out to determine the mechanical properties of the treated rubber [8].

Kaolinite, an important industrial raw material, has a wide variety of applications in industry, particularly in paper 
TABLE 1: The composites of SBR adhesives with and without red kaolinite additive.

\begin{tabular}{lcc}
\hline Material & $\begin{array}{c}\text { Adhesive with red } \\
\text { kaolinite }\end{array}$ & $\begin{array}{c}\text { Adhesive without } \\
\text { red kaolinite }\end{array}$ \\
\hline $\begin{array}{l}\text { SBR }(\mathrm{g}) \\
\begin{array}{l}\text { Solvent of } \\
\text { dichloromethane }(\mathrm{mL})\end{array}\end{array}$ & $60(\mathrm{~g})$ & $60(\mathrm{~g})$ \\
$\begin{array}{l}\text { Kaolinite } \\
\left(\mathrm{Al}_{2} \mathrm{Si}_{2} \mathrm{O}_{5}(\mathrm{OH})_{4}\right)(\mathrm{g})\end{array}$ & $30(\mathrm{~mL})$ & $500(\mathrm{~mL})$ \\
\hline
\end{tabular}

filler and coating pigment [9]. It is used as an extender in aqueous-based paints and inks, a functional additive in polymers and is the major component in ceramics [10]. Kaolinite is a dioctahedral 1:1 phyllosilicate formed by superposition of silicon tetrahedral sheets and aluminum octahedral sheets. Adjacent layers are linked by van der Waals forces and hydrogen bonds. This interlayer induces restricted access to the interlamellar aluminol groups $(\mathrm{Al}-\mathrm{OH})$ that may be used for grafting reactions. The most reactive functional groups in kaolinite are hydroxyl groups, which are capable of taking part in many chemical reactions as well as ion exchange processes [11].

The aim of this work is to study the effectiveness of adhesion of SBR with and without kaolinite on the Aluminum surface at temperature of $200{ }^{\circ} \mathrm{C}$ and at different time (10$50 \mathrm{~min})$. To know the convenience of styrene-butadiene rubber adhesive with and without additive in aluminum industries, the shear stress, strain, modulus, and images of adhesives were studied on the aluminum surfaces.

\section{Experimental}

2.1. Materials. Styrene-butadiene rubber (SBR 1502 nonstaining) as the product of Bayer AG (Germany) was; used it has the following characteristics: styrene content $23.5 \%$ with specific gravity $1.17, T_{g}-60^{\circ} \mathrm{C}$, and Mooney viscosity $\mathrm{M}_{L}(1$ $+4), 52 \pm 3$ at $100^{\circ} \mathrm{C}$. Dichloromethane, with mass fraction purity of more than 0.997 , was purchased from Guangdong Guanghua Sci-Tech Co., Ltd., China. The kaolinite was purchased from Geological Survey and Mineral Investigation Company, the Ministry of Industry, Iraq.

2.2. The Adhesive Formulations. The SBR adhesives composites with and without red kaolinite additive were mentioned in Table 1.

2.3. The Method of Preparation of SBR Adhesive. The SBR resin was cut to small pieces and these small pieces were mixed with dichloromethane solvent and were left for 5 days at room temperature with continuous well stirring until the mixture became homogenous. For SBR adhesive with kaolinite $\left(\mathrm{Al}_{2} \mathrm{Si}_{2} \mathrm{O}_{5}(\mathrm{OH})_{4}\right)$ additive, the kaolinite material was added to above homogenous mixture with continuous well stirring at room temperature until good mixture was obtained. The specimens were attended according to the ASTM (D1002) for testing shear stress and the specimens were left to dry at room temperature for 1 day. After that, the specimens were cured at the temperatures of $200^{\circ} \mathrm{C}$ and at different times (10, 30, 40 and $50 \mathrm{~min})$. The specimens were left to cool at room temperature to make the convenience tests.

2.4. Preparation of the Aluminum Surface. Firstly, it was cleaned the aluminum surface by blasting with abrasive papers (No: 1000) to remove contamination and to make the surface rough. Second, use a procedure of Ciba Composites as described below [12].

(a) Vapor degreasing in dichloromethane solvent is carried out for $10 \mathrm{~min}$ at $70^{\circ} \mathrm{C}$, followed by a spray rinse in clean water.

(b) Etch in sodium dichromate $375 \mathrm{~g}$, concentrated sulfuric acid $750 \mathrm{~mL}$, and water to $51 \mathrm{~mL}$, at $60^{\circ} \mathrm{C}$ for $30 \mathrm{~min}$.

(c) Immerse in a tank of ambient water.

(d) Spray rinse with cold water.

(e) Dry in an air-circulating oven at $45^{\circ} \mathrm{C}$.

(f) Bonding should take place within $8 \mathrm{~h}$.

2.5. Mechanical Properties. The tensile strength, elongation at break, and Young's modulus were determined with a Gunt WP300.20 testing machine (Hamburg, Germany). The specimens were tested at a crosshead, speed of $50 \mathrm{~mm} / \mathrm{min}$ according to ASTM (D1002) for determination of mechanical properties.

\section{Results and Discussions}

The forces of styrene-butadiene rubber adhesive with and without kaolinite were studied on the aluminum surface to know the convenience of it in aluminum industries. All specimens were dried at room temperature for one day after preparing them. After that the SBR adhesive specimen without additives was cured at temperature $200^{\circ} \mathrm{C}$ for a period of time of $10 \mathrm{~min}$. The results showed that the maximum shear stress was $1.4 \mathrm{kPa}$ at strain of 0.33 and at modulus of $22.5 \mathrm{kPa}$ as shown in Figure 1. It should be noted that in uniaxial loading, the stress $(S)$ is simply the force $(F)$ divided by the cross-sectional area $(A)$ and the strain, $E$, is the deformation $(L)$ divided by the original length $\left(L_{o}\right)$. The modulus $(M)$ of the material is then the ratio of stress/strain $[13,14]$ :

$$
\begin{gathered}
\text { Stress, } S=\frac{F}{A}, \\
\text { Strain (Elongation), } E=\frac{L}{L_{\mathrm{o}}}, \\
\text { Modulus, } M=\frac{S}{E} .
\end{gathered}
$$

It is found that the adhesive acts as ductile polymer $[14,15]$ as shown in Figure 1.

On the other hand, when SBR adhesive without additives was cured at temperature of $200^{\circ} \mathrm{C}$ and at curing time of 


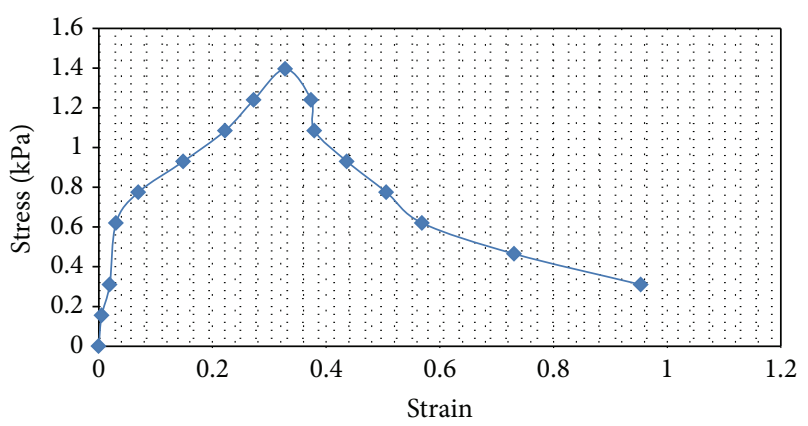

FIGURE 1: Stress-strain of styrene-butadiene rubber adhesive without additive at curing temperature of $200^{\circ} \mathrm{C}$ for period of time of $10 \mathrm{~min}$.

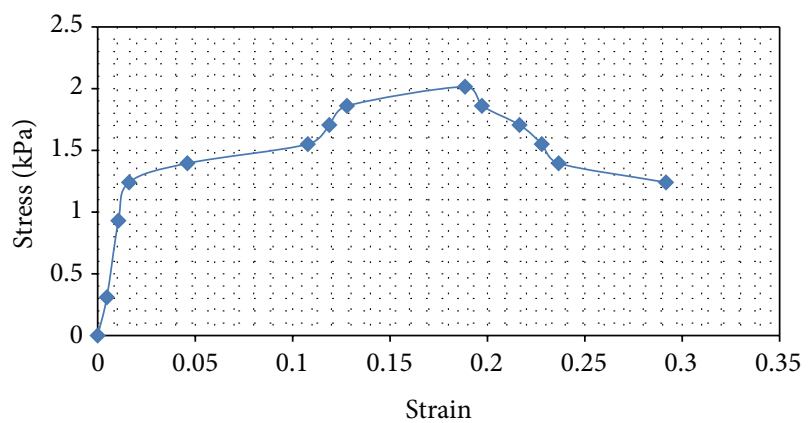

FIGURE 2: Stress-strain of styrene-butadiene rubber adhesive without additive at curing temperature of $200^{\circ} \mathrm{C}$ for period of time of $30 \mathrm{~min}$.

30 min on the aluminum surface, it is found the maximum shear stress of $2 \mathrm{kN} / \mathrm{m}^{2}, 0.19$ strain, and $24 \mathrm{kN} / \mathrm{m}^{2}$ modulus as shown in Figure 2. Also we can see from Figure 2 that the adhesive materials act as elastomeric polymer [14, 15].

Moreover, it was found that the maximum shear stress of adhesive was $2.3 \mathrm{KN} / \mathrm{m}^{2}$ at two point in strain axis $(0.052$ and 0.23 ) when curing SBR adhesive without additives at temperature of $200^{\circ} \mathrm{C}$ and at curing time of $40 \mathrm{~min}$. The reason of this phenomenon may be that the polymer molecules orientate at strain value of $0.23[13,15]$ while the modulus highly increased than previous curing conditions to be $100 \mathrm{KN} / \mathrm{m}^{2}$. The reason may be that curing time of $40 \mathrm{~min}$ caused the orientation of polymer molecules to increase the crystallinity of SBR more than other conditions of curing. From Figure 3, it may be concluded that the adhesive materials act as ductile materials $[14,15]$.

Furthermore, it was found that the maximum shear stress was $1.71 \mathrm{kN} / \mathrm{m}^{2}$, at strain of 0.19 and the modulus was $300 \mathrm{kN} / \mathrm{m}^{2}$ when SBR adhesive without additives was cured at temperature of $200^{\circ} \mathrm{C}$ and at period of time of $50 \mathrm{~min}$ on the aluminum surface as shown in Figure 4 . Also we can see from Figure 2 that the adhesive material acts as elastomeric polymer $[14,15]$.

Figure 5 exhibited the images of adhesive styrenebutadiene rubber without additive curing at temperature $200^{\circ} \mathrm{C}$ and at different periods of time (10,30, 40, and $\left.50 \mathrm{~min}\right)$. As it is seen from Figures 5(a1), 5(a2), 5(a3), and 5(a4), the

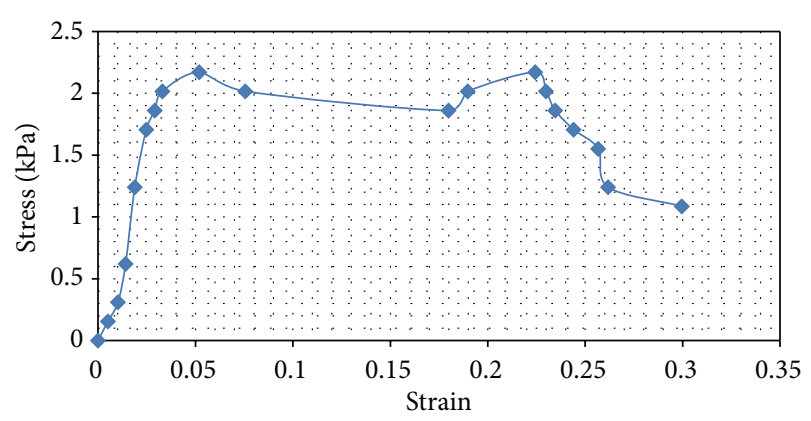

FIGURE 3: Stress-strain of styrene-butadiene rubber adhesive without additive at curing temperature of $200^{\circ} \mathrm{C}$ for period of time of $40 \mathrm{~min}$.

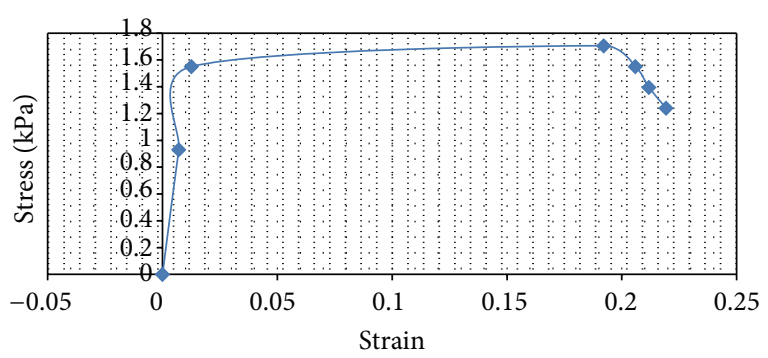

FIGURE 4: Stress-strain of styrene-butadiene rubber adhesive without additive at curing temperature of $200^{\circ} \mathrm{C}$ for period of time of $50 \mathrm{~min}$.

failure in adhesive was due to failure in the adhesion between the polymer and the aluminum surface as well as the failure of polymer cohesive energy.

Figure 6 showed the maximum shear stress and strain of adhesive at different curing times and at constant curing temperature of $200^{\circ} \mathrm{C}$. It was noted that the maximum shear stress increases with an increase the curing time and the highest maximum shear stress was observed at curing time of $40 \mathrm{~min}$ that may be attributed to the increase in the ionic bonds between the rubber and metal at curing time of $40 \mathrm{~min}$ under temperature of $200^{\circ} \mathrm{C}$. On the other hand, the shear stress decreases at curing time of 50 min that may be due to degradation of the adhesive material in these circumstances, as shown in Figure 6. Further, the strains at different curing times $(10,30,40$, and $50 \mathrm{~min})$ and at constant curing temperature $200^{\circ} \mathrm{C}$ were slightly decreased with increasing the time, as shown in Figure 6.

It was showed that the modulus of SBR adhesive without additives increases with increasing curing time (10, 30, 40, and $50 \mathrm{~min}$ ) and at a constant curing temperature of $200^{\circ} \mathrm{C}$ as shown in Figure 7. After breaking of samples, the two sticking parts of sample were immersed in dichloromethane solvent for one day at room temperature. It was observed that no swelling was shown in adhesive materials but the adhesive materials dissolved in the solvent of dichloromethane; therefore, no cross-linking was detected in adhesive materials according to no swelling occurrence. For these reasons, it may be the increasing modulus with increasing curing 


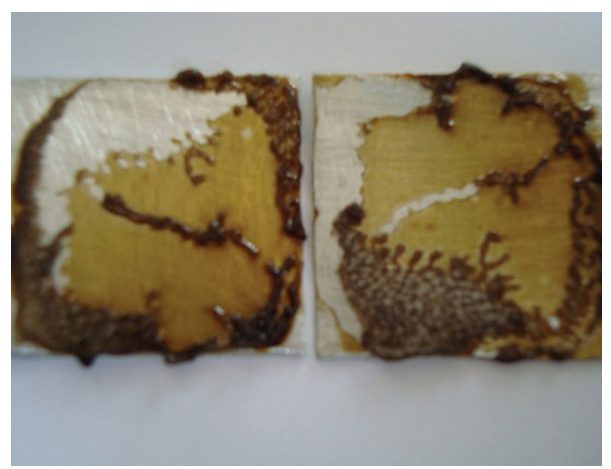

(a1)

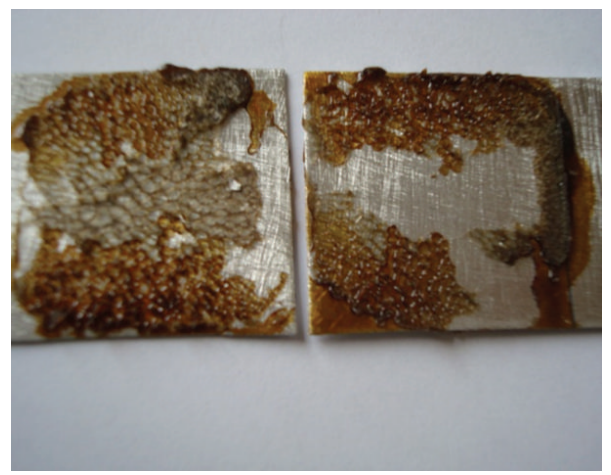

(a3)

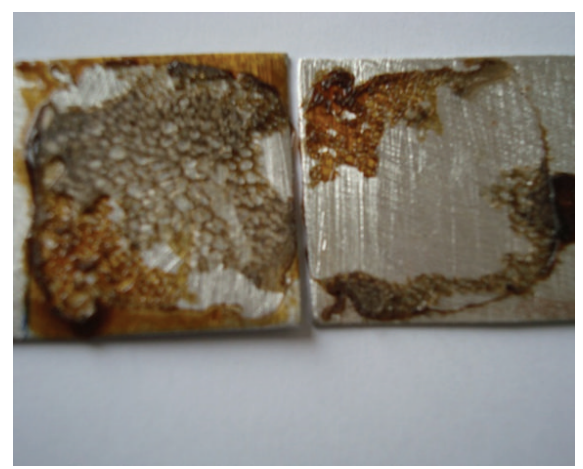

(a2)

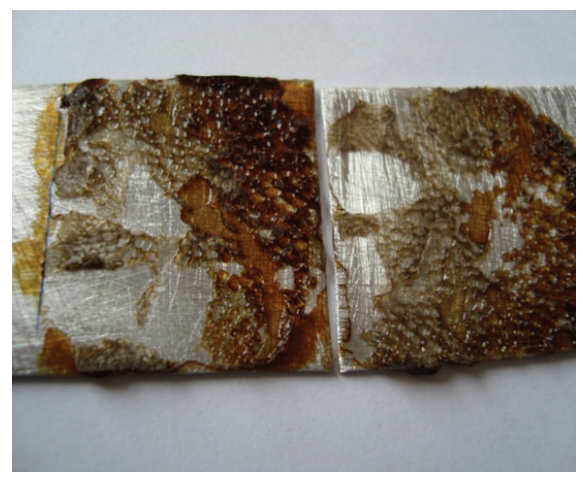

(a4)

FIGURE 5: Styrene-butadiene rubber adhesive without additive at curing temperature of $200^{\circ} \mathrm{C}$ and periods of times (a1) $10 \mathrm{~min}$, (a2) $30 \mathrm{~min}$, (a3) $40 \mathrm{~min}$, and (a4) $50 \mathrm{~min}$.

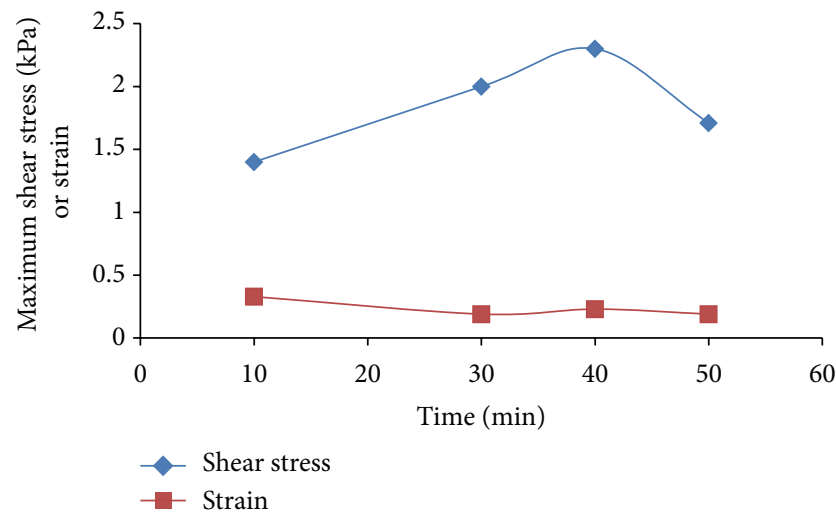

FIGURE 6: Shear stress $(\mathrm{kPa})$ and strain versus time (min) of styrenebutadiene rubber adhesive without additive at curing temperature of $200^{\circ} \mathrm{C}$.

times because the polymer molecules were orientation in unidirectional.

Furthermore, the SBR adhesive with $50 \mathrm{wt} \%$ kaolinite was cured at temperature of $200^{\circ} \mathrm{C}$ and at different periods of times of $10,20,30,40$, and $50 \mathrm{~min}$ on the aluminum surface. The results showed that the forces of adhesives on the surface of aluminum were very poor in all mentioned conditions except at curing time of $40 \mathrm{~min}$ and also they had poor adhesion where the maximum shear stress was $0.47 \mathrm{kN} / \mathrm{m}^{2}$ with strain of 0.25 as shown in Figure 8. In addition, we can

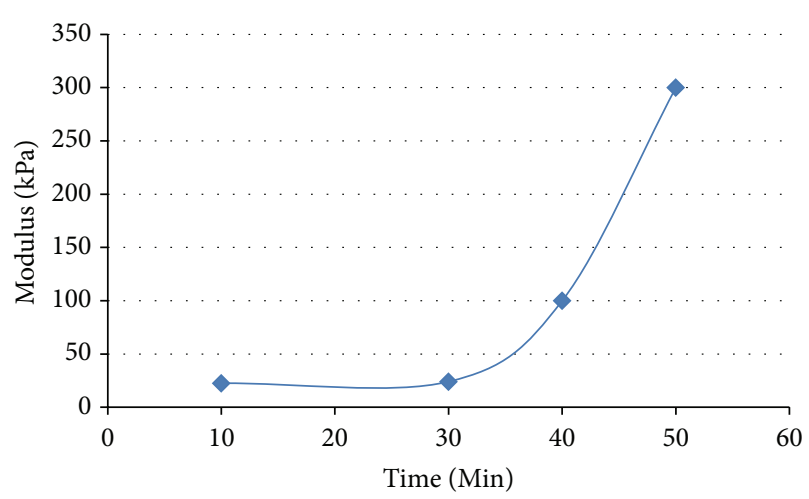

FIgURE 7: Modulus $(\mathrm{kPa})$ versus curing time $(\mathrm{min})$ of styrenebutadiene rubber adhesive without additive at curing temperature $200^{\circ} \mathrm{C}$.

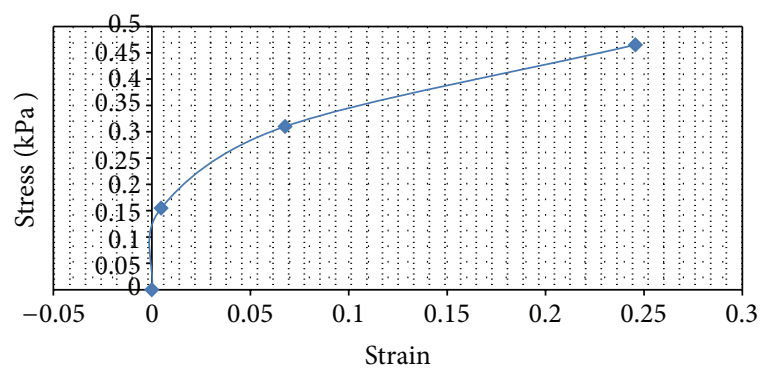

FIGURE 8: Stress-strain of styrene-butadiene rubber adhesive with $50 \mathrm{wt} \%$ kaolinite at curing temperature of $200^{\circ} \mathrm{C}$ for period of time of $40 \mathrm{~min}$. 


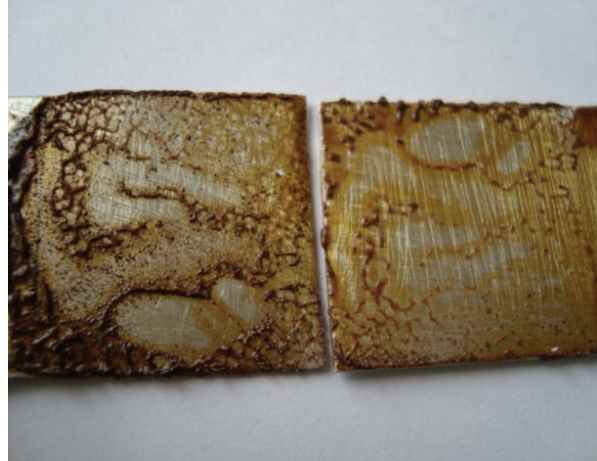

(a1)

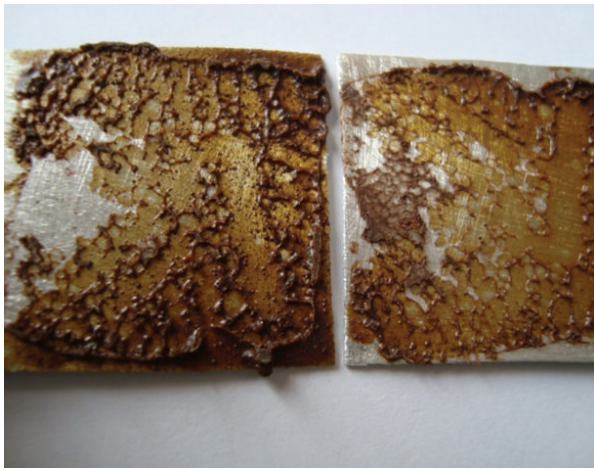

(a3)

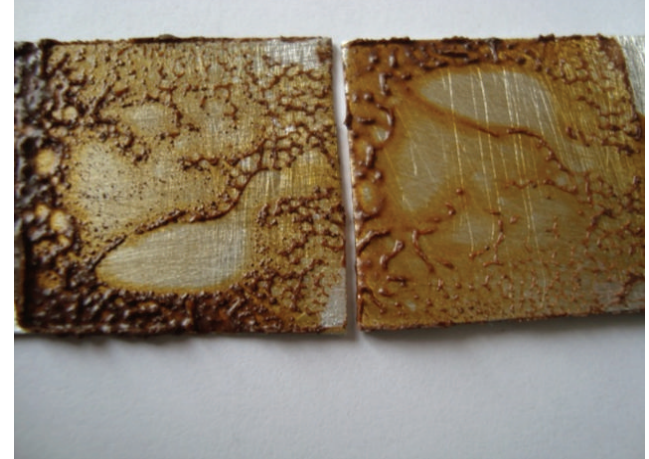

(a2)

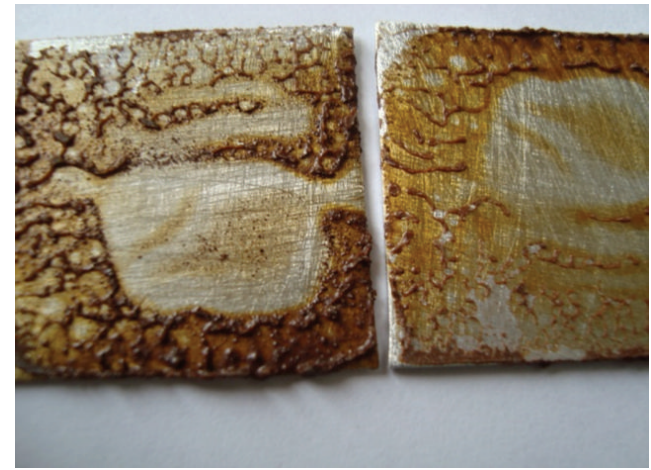

(a4)

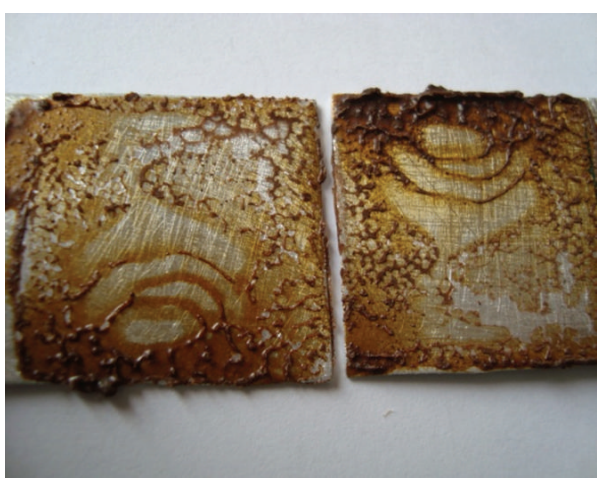

(a5)

Figure 9: Styrene-butadiene rubber with additive ( $50 \%$ by weight) kaolinite adhesive curing at temperature $200^{\circ} \mathrm{C}$ and periods of time of (al) $10 \mathrm{~min}$, (a2) $20 \mathrm{~min}$, (a3) $30 \mathrm{~min}$, (a4) $40 \mathrm{~min}$, (a5) $50 \mathrm{~min}$.

conclude from Figure 8 that the adhesive materials act as elastomeric polymer $[14,15]$.

Figure 9 exhibits the break samples of styrene-butadiene rubber $/ 50 \mathrm{wt} \%$ kaolinite adhesives at curing temperature of $200^{\circ} \mathrm{C}$ and at different periods of time $(10,20,30,40,50 \mathrm{~min})$. As it is seen from Figures 9(a1), 9(a2), 9(a3), 9(a4), and 9(a5), the failure of adhesives attributed to failure of cohesive energy; in addition, the adhesion of adhesives with aluminum surface was very good. It is clear from Figure 9 that the adhesion of SBR on aluminum surface was improved by adding kaolinite leading to very good adhesion. Moreover, it can be concluded from images in Figure 9 that the failure of adhesive with kaolinite additive was due to the cracking in polymer molecular. Thus, the expectation for the adhesive success to give good force that it must added new polymer between two layers of SBR/kaolinite adhesive that a new polymer should achieve good adhesion with SBR/kaolinite adhesive.

\section{Conclusions}

(1) The best adhesion for SBR adhesive without kaolinite additive on the aluminum surfaces was at curing temperature of $200^{\circ} \mathrm{C}$ for period of time of $40 \mathrm{~min}$.

(2) The shear stress of SBR adhesive on the aluminum surfaces was very weak when the kaolinite material was added to it. 
(3) The failure of adhesives without additives was due to both adhesion and cohesive energy of adhesives.

(4) The failure of adhesives with kaolinite additive was attributed to cohesive energy of adhesives. Therefore for improvement of adhesive force, other materials must be used to develop the cohesive energy of adhesives.

\section{Conflict of Interests}

The authors declare that there is no conflict of interests regarding the publication of this paper.

\section{References}

[1] J. Miguel Martín-Martínez, "Rubber base adhesives," in Adhesion Science and Engineering, M. Chaudhury and A. V. Pocius, Eds., chapter 13, pp. 573-675, Elsevier Science B.V., Amsterdam, The Netherlands, 2002.

[2] C. García-Martín, V. Andreu-Gómez, and J. Miguel MartínMartínez, "Surface modification of vulcanized styrenebutadiene rubber with trichloroisocyanuric acid solutions of different active chlorine contents," International Journal of Adhesion and Adhesives, vol. 30, no. 7, pp. 550-558, 2010.

[3] F. Zhang and J. Yu, "The research for high-performance SBR compound modified asphalt," Construction and Building Materials, vol. 24, no. 3, pp. 410-418, 2010.

[4] Y. Yildirim, "Polymer modified asphalt binders," Construction and Building Materials, vol. 21, no. 1, pp. 66-72, 2007.

[5] K. Maeda, A. Bismarck, and B. Briscoe, "Effect of bulk deformation on rubber adhesion," Wear, vol. 263, no. 7-12, pp. 1016-1022, 2007.

[6] M. D. Romero-Sánchez and J. M. Martín-Martínez, "Surface modifications of vulcanized SBR rubber by treatment with atmospheric pressure plasma torch," International Journal of Adhesion and Adhesives, vol. 26, no. 5, pp. 345-354, 2006.

[7] S. G. Abbott, D. M. Brewis, N. E. Manley, I. Mathieson, and N. E. Oliver, "Solvent-free bonding of shoe-soling materials," International Journal of Adhesion and Adhesives, vol. 23, no. 3, pp. 225-230, 2003.

[8] M. D. Romero-Sánchez, M. M. Pastor-Blas, and J. M. MartínMartínez, "Adhesion improvement of SBR rubber by treatment with trichloroisocyanuric acid solutions in different esters," International Journal of Adhesion and Adhesives, vol. 21, no. 4, pp. 325-337, 2001.

[9] W. N. Martens, R. L. Frost, J. Kristof, and E. Horvath, "Modification of kaolinite surfaces through intercalation with deuterated dimethylsulfoxide," Journal of Physical Chemistry B, vol. 106, no. 16, pp. 4162-4171, 2002.

[10] H. H. Murray, "Traditional and new applications for kaolin, smectite, and palygorskite: a general overview," Applied Clay Science, vol. 17, no. 5-6, pp. 207-221, 2000.

[11] H. Ming, "Modification of kaolinite by controlled hydrothermal deuteration-a DRIFT spectroscopic study," Clay Minerals, vol. 39, no. 3, pp. 349-362, 2004.

[12] J. Comyn, RSC Paperbacks Adhesion Science, The Royal Society of Chemistry, Cambridge, UK, 1997.

[13] R. J. Crawford, Plastics Engineering, Butterworth-Heinemann, Oxford, UK, 3rd edition, 2002.
[14] L. E. Nielsen and F. Robert, Landel, Mechanical Properties of Polymers and Composites, Marcel Dekker, Inc, 2nd edition, 1994.

[15] D. I. Bower, An Introduction to Polymer Physics, Cambridge University Press, Cambridge, UK, 2002. 

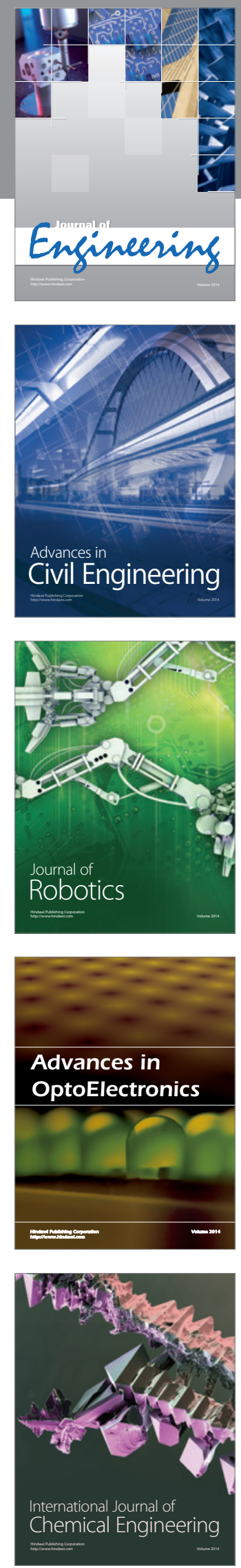

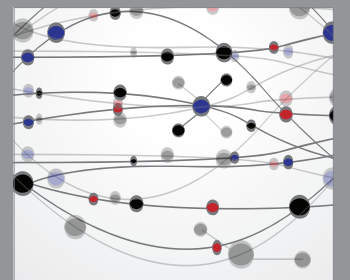

The Scientific World Journal
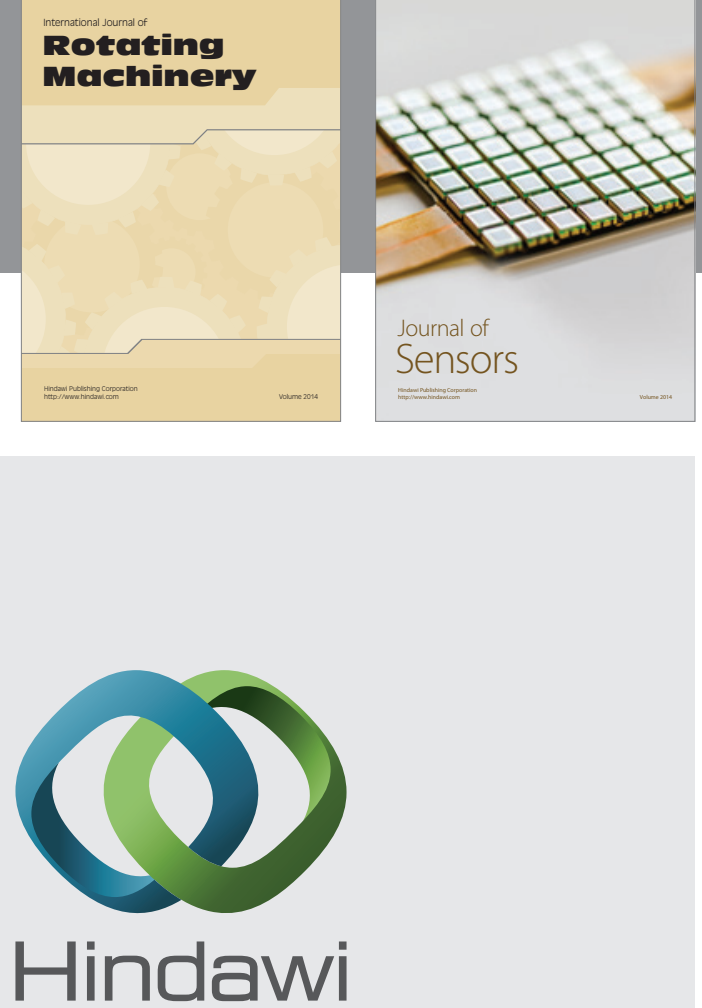

Submit your manuscripts at http://www.hindawi.com
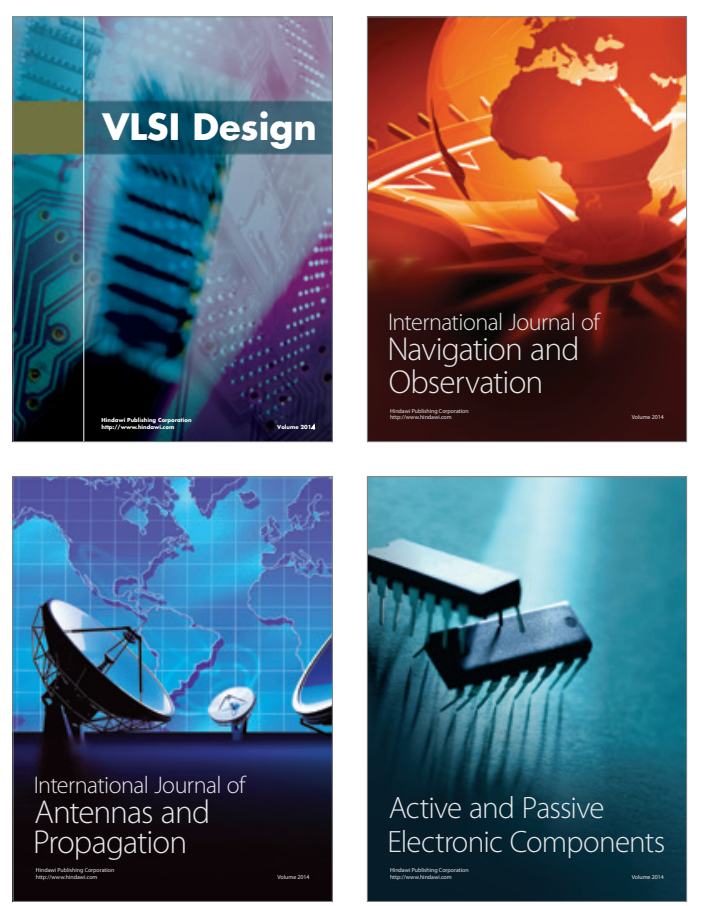
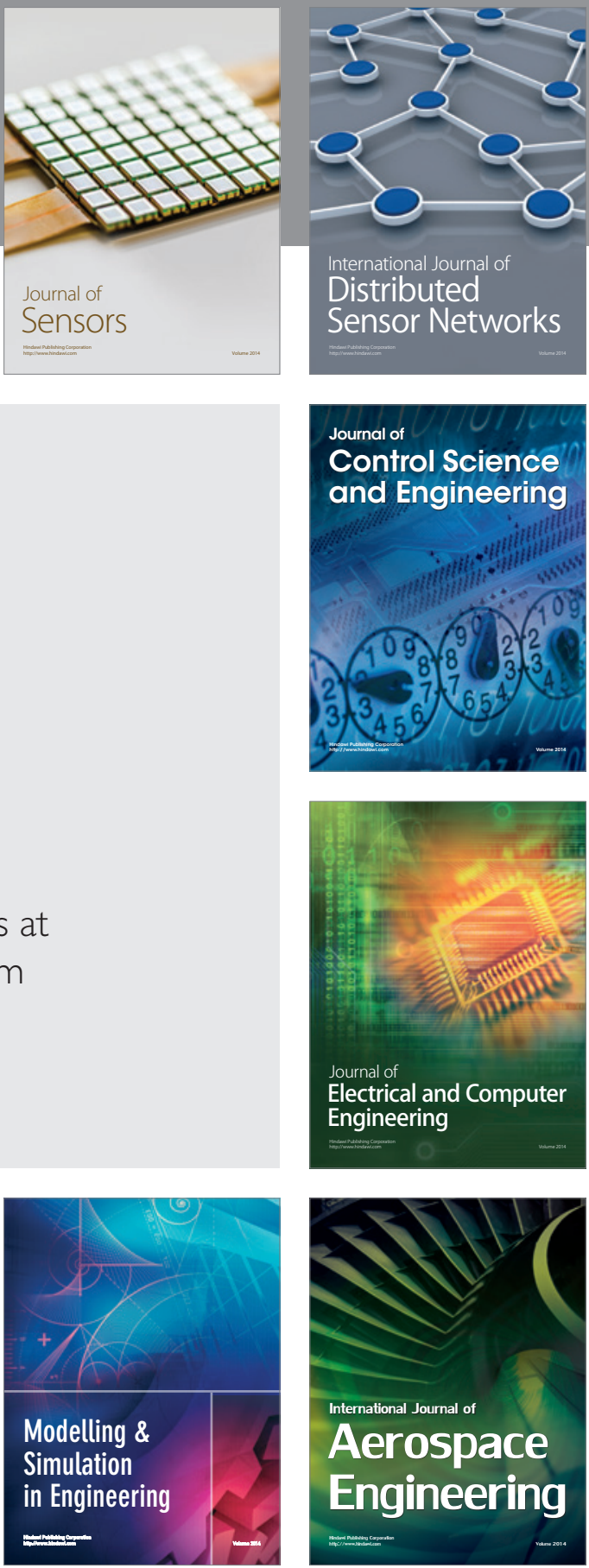

Journal of

Control Science

and Engineering
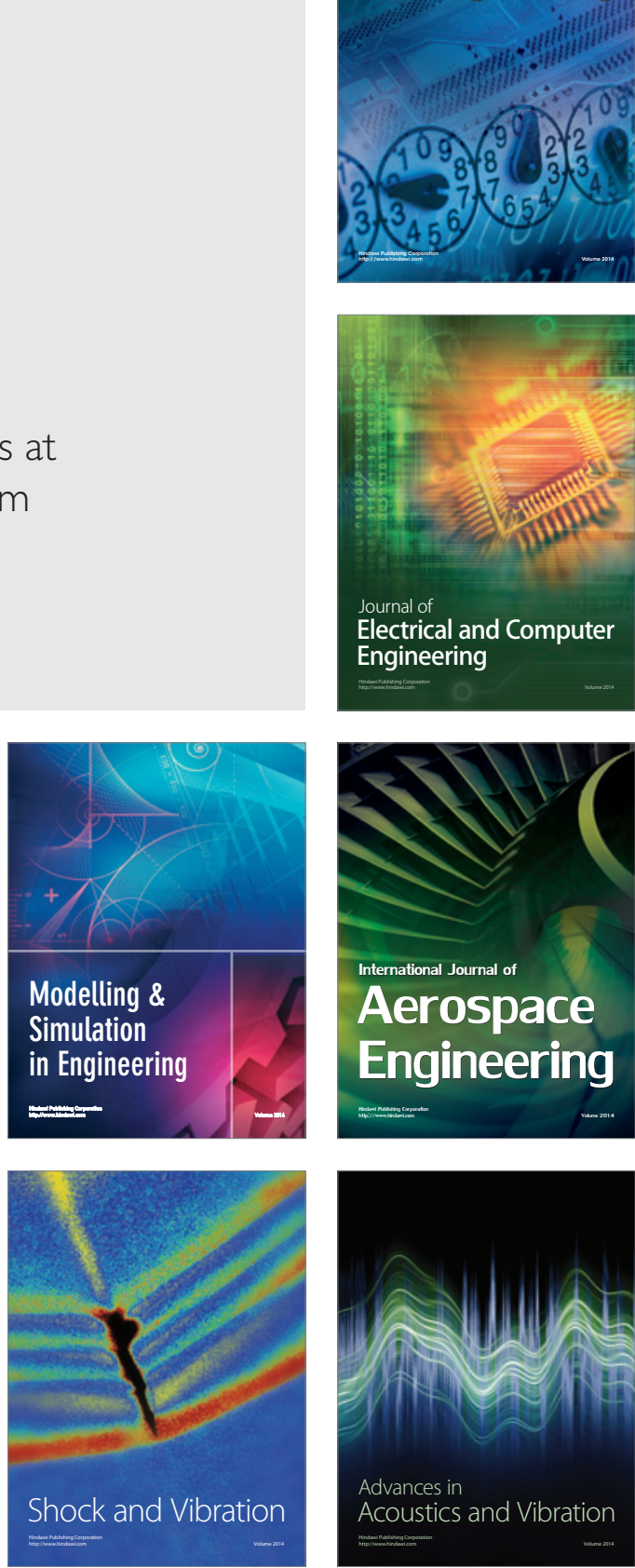